\title{
Cientistas na TV: como homens e mulheres da ciência são representados no Jornal Nacional e no Fantástico*
}

\section{Resumo}

\author{
Luisa Massarani** \\ Yurij Castelfranchi*** \\ Anna Elisa Pedreira****
}

Neste trabalho, no âmbito da extensa literatura sobre mulheres $e$ ciência, investigamos um território menos explorado no Brasil: o das representações de mulheres cientistas em programas televisivos de grande audiência. Lançando mão de uma triangulação metodológica de técnicas quantitativas e qualitativas, incluindo análise de conteúdo e análise visual, estudamos, por 12 meses, dois programas de grande audiência na TV: o Jornal Nacional e o Fantástico. Os resultados mostram, por um lado, uma presença importante de jovens cientistas mulheres, mas, por outro, uma construção discursiva que remete claramente a um universo científico majoritariamente masculino, com protagonistas predominantemente brancos e de meia idade. Vozes e presença das mulheres tendem a ser sub-representadas $e$ pouco visíveis, além de aparecer com conotações simbólicas diferentes da dos homens, reproduzindo hierarquias e estereótipos. Evidenciamos também os efeitos que os diferentes contextos de produção e os registros estéticos dos dois programas têm sobre as representações de gênero.

Palavras-chave: $\quad$ Estudos Sociais da Ciência, Representações Midiáticas, Ciência e TV, Estudos de Gênero, Jornalismo Científico.

* Recebido em 10 de maio de 2016, aceito em 14 de novembro de 2018.

** Pesquisadora no Instituto Nacional de Comunicação Pública da Ciência e Tecnologia e Fundação Oswaldo Cruz; cientista do Nosso Estado (FAPERJ), Rio de Janeiro, RJ, Brasil. luisa.massarani6@gmail.com / https://orcid.org/0000-0002-5710-7242 *** Pesquisador no Instituto Nacional de Comunicação Pública da Ciência $e$ Tecnologia; Professor no Programa de Pós-Graduação em Sociologia, na UFMG, Belo Horizonte, MG, Brasil. yurijcastelfranchi@gmail.com / https://orcid.org/00000003-4003-5956.

**** Doutoranda em Ciências da Comunicação, Universidade do Minho (Uminho), Braga, Portugal. annaelisapedreira@hotmail.com / https://orcid.org/0000-0001-7272$\underline{0216}$ 


\title{
Scientists on TV: How Men and Women Scientists Are Represented on the Programs Jornal Nacional and Fantástico
}

\begin{abstract}
In this paper, within the scope of the extensive literature on women and science, we investigate a territory that is less explored in Brazil: the representations of female scientists in widely viewed TV programs. Using a methodological triangulation of quantitative and qualitative techniques, including content analysis and visual analysis, we analyzed, during 12 months, two of Brazil's highest-rated television programs: the Jornal Nacional and Fantástico. While the results found an important presence of young female scientists, they identified a discursive construction that clearly refers to a predominantly male scientific universe with predominantly white and middle-aged protagonists. Women's voices and presence tend to be under-represented and poorly visible, and appear with symbolic connotations different from those of men, which reproduce hierarchies and stereotypes. We also show the influence of the different production contexts and aesthetic registers of the two programs on the representations of gender.
\end{abstract}

Keywords: Social Studies of Science, Media Representations, Science and TV, Gender Studies, Science Journalism. 
Introdução: os desafios das mulheres cientistas

Nas últimas décadas, tanto na área transdisciplinar dos estudos de gênero, como nos territórios das políticas de C\&T ou dos estudos sociais da $\mathrm{C} \& \mathrm{~T}$, atenção crescente foi dada às presenças $e$ às ausências, à visibilidade $e$ à invisibilização das mulheres nas ciências. No Brasil e na América Latina, emergiu uma literatura vasta $e$ articulada sobre gênero e ciência, bem como sobre mulheres na esfera pública e nas políticas públicas. Contudo, existem poucas pesquisas, na região latino-americana, sobre as representações midiáticas das mulheres cientistas, e sobre a construção jornalística de narrativas sobre gênero e ciência. Este trabalho pretende contribuir para preencher essa lacuna.

Estudos recentes apontam para a desmistificação da ciência brasileira como espaço masculino e demonstram a inserção institucionalizada das mulheres em laboratórios e grupos de pesquisa no Brasil, sobretudo, após a Segunda Guerra Mundial (Abreu, 2010; Ferreira et alii, 2008; Guedes, 2008; Melo, Oliveira, 2006; Luz, 2009; Grossi, 2016). No entanto, no Brasil e no mundo, a atividade científica continua sendo pouco associada ao universo feminino: a metáfora baconiana da ciência como Temporis partus masculus (o "parto masculino do tempo") e a convicção de Immanuel Kant de que uma pessoa envolvida em atividade intelectual séria deveria "ter barba" parecem ainda vivas no mundo ocidental (ver Keller, 1985:51; Schienbinger, 2001:138).

No Brasil, na avaliação de Abreu (2010), de uma maneira geral, avançou-se muito no que se refere às questões de gênero $e$ na redução nas diferenças entre os dois sexos. As mulheres constituem $44 \%$ da força de trabalho, $55 \%$ dos estudantes universitários brasileiros e $60 \%$ daqueles que obtêm o certificado de graduação.

Segundo o Conselho Nacional de Desenvolvimento Científico e Tecnológico (CNPq), conforme o censo de 2014, o número de mulheres cientistas era o mesmo que o de homens no país (ver CNPq, "Séries Históricas por Pesquisadores por sexo"). Pesquisadoras mulheres têm predominância nas áreas de Ciências 
Humanas e Sociais; as Ciências Exatas são dominadas pelos homens, principalmente as Engenharias. Há um equilibrio entre gêneros nas áreas de Saúde e Biológicas.

No entanto, segundo o $\mathrm{CNPq}$, o número de mulheres cientistas é um pouco inferior em comparação ao de homens quando se analisa a liderança dos grupos de pesquisa (46\%, ver $\mathrm{CNPq}$, Séries Históricas por Pesquisadores por liderança e sexo). Abreu (2010) sinaliza, ainda, que a presença feminina entre os pesquisadores contemplados com Bolsas Produtividade do CNPq em todos os seus cinco níveis é reduzida: em 2008, era de aproximadamente $30 \%$ das bolsas concedidas na última década; esse número é cerca de $20 \%$ quando consideramos o nível mais alto, 1A (ver também Guedes, Azevedo e Ferreira, 2015). Melo e Oliveira (2006), por sua vez, mostram que apenas $32,3 \%$ dos artigos publicados na base Scielo foram escritos por mulheres, segundo estudo realizado em 2006. Também é reduzida a presença de mulheres na Academia Brasileira de Ciências: apenas $13,3 \%$ de seus membros.

Abreu (2010) aponta, também, que nenhuma mulher ocupou ainda o cargo de ministra de ciência e tecnologia no Brasil (como é o caso em alguns países da América Latina e Caribe) ou de presidente nas principais agências de fomento do país embora o país tenha tido uma presidente mulher.

No âmbito sociológico, o funcionamento dos processos de estratificação social e discriminação na organização institucional da ciência e na produção do conhecimento é também tema central para a cientometria e a sociologia da C\&T, desde os estudos pioneiros de Derek de Solla Price (1986) sobre a concentração das citações entre poucos autores e instituições, e de Robert K. Merton e seus colegas sobre a formação do prestígio acadêmico e da "vantagem cumulativa" (o chamado "Efeito Mateus") dos cientistas e das instituições de renome (Merton, 1973; Zuckermann, 1977). Especialmente a partir da década de 1980, ficou evidente que tais processos de estratificação do poder e do prestígio tinham uma profunda conotação de gênero, sendo para as mulheres, em praticamente todos os países do mundo, 
marcadamente mais difícil o acesso às carreiras científicas (Rossiter, 1982), a permanência nessas carreiras e a ascensão a posições de prestígio e poder (Delamont, 1989; Glover, 2000), especialmente aquelas de gate keepers, tais como editora de revistas, lideranças em comitês de avaliação etc. Além disso, estudos mostraram como as representações masculinas associadas à ciência e à tecnologia influenciam a percepção de jovens mulheres e sua motivação ou possibilidades de tornar-se cientistas ou ver-se como cientistas (Easlea 1986; Faulkner 2007), bem como o papel desencorajador exercido por professores, pais e colegas na escola (Orenstein 1994; para uma revisão da literatura, ver também Sismondo, 2010).

Se, por um lado, a discussão sobre desigualdades de gênero na ciência no Brasil e na América Latina é ampla e aprofundada (ver, por exemplo, Tabak, 2002; Luz, 2009; Grossi et alii, 2016; Lima e Costa, 2016; Freitas; Luz, 2017), menos explorados na região foram os territórios, importantes, das representações midiáticas sobre gênero e ciência e das sub-representações de mulheres cientistas na mídia nacional, que são o foco deste trabalho.

\section{Cientistas, gênero e representações}

Diversos estudos internacionais apontam o potencial da mídia para reproduzir e reforçar estereótipos sociais (Lobo, 2010; Chimba, Kitzinger, 2010; Rivadeneyra, 2006; Davies et alii, 2002; Potts, Martinez, 1994; Durkin, 1984). No Brasil, Biroli (2010), ao estudar as relações entre gênero e política em revistas semanais brasileiras, demonstra não apenas a presença reduzida das mulheres políticas na mídia, mas, também, a convivência entre tal sub-representação e "a existência de estereótipos de gênero que remetem a compreensões menos ou mais convencionais do papel da mulher nas sociedades e de sua competência para atuar na vida pública" (Biroli, 2010:269). A autora demonstra, no caso da política, que no contexto "de produção de silêncios e de uma visibilidade que toma forma a partir de filtros comuns" (Biroli, 2010:273), "as mulheres são, predominantemente, invisíveis no noticiário". E, segundo a autora, quando há visibilidade, ela "é concentrada em 
algumas poucas mulheres e produzida por filtros que reafirmam, de múltiplas maneiras, as separações tradicionais que associam as mulheres à esfera doméstica e íntima, à emotividade e ao corpo" (Biroli, 2010:273). De acordo com o documento "Pensando Gênero e Ciência - Encontro Nacional de Núcleos e Grupos de Pesquisa", publicado pela Secretaria Especial de Políticas para as Mulheres como resultado de encontro homônimo realizado em 2006 em Brasília, a mídia pode ter um papel fundamental na construção da imagem da mulher cientista $e$ poderia contribuir com ações de divulgação e popularização das ciências levando em conta perspectivas de gênero. $\mathrm{O}$ mesmo documento aponta a necessidade de se investigar os valores sociais relacionados à atividade científica transmitidos pelos meios de comunicação, na tentativa de elucidar alguns dos fatores que podem desencorajar as jovens a buscarem carreiras científicas.

Preocupações análogas se encontram nos programas e nas políticas públicas da União Europeia (EU). Em 2012, Máire Geoghegan-Quinn, então comissária da UE para Pesquisa, Inovação e Ciência, lançou campanha visando incentivar um número maior de mulheres a optarem por carreiras de pesquisa, composta de duas fases. ${ }^{1}$ A primeira, sob o lema Science: It's a girl thing! (Ciência é coisa de menina), destina-se a jovens de 13 a 18 anos, e teve como objetivo incentivar o contato (presencial ou online) com mulheres cientistas, enfatizando os aspetos empolgantes $e$ os desafios que a carreira de cientista ou engenheira implica. A segunda fase da campanha focou em jovens universitárias e procurou incentivar a escolha da pesquisa como carreira. A campanha dedicou atenção à mídia e à comunicação da Web 2.0, produzindo, entre outras peças, um videoclipe que

1 De acordo com o portal da campanha: "As mulheres constituem mais de metade da população estudantil da UE e representam mais de $45 \%$ de todos os doutoramentos, mas perfazem apenas um terço dos investigadores de carreira, tendo uma representação muito reduzida em nível de cargos de chefia. A Europa necessita de mais investigação $e$ inovação para estimular o crescimento $e$ a criação de empregos, pelo que a sub-representação das mulheres na investigação é injusta e negativa para o crescimento econômico" (Comissão Europeia, 2013). 
suscitou controvérsias, por se considerar que, na verdade, estaria reproduzindo estereótipos e preconceitos de gênero. ${ }^{2}$

No cenário internacional, alguns estudiosos vêm se dedicando a investigar as representações de gênero de cientistas em distintos veículos de comunicação, entre elas a norteamericana Jocelyn Steinke (Ver, por exemplo, Steinke, 2004, 2005, Steinke et alii, 2011; ver também Long et alii, 2010). Segundo a autora, embora a representação midiática das mulheres cientistas tenha melhorado recentemente, no sentido de ser menos estereotipada, muitos personagens femininos midiáticos ainda são representados como sendo mais preocupados com a aparência e o romance que com questões acadêmicas ou relacionadas a sua carreira profissional. Após analisar 74 filmes populares em que cientistas são personagens principais, Steinke (2005) conclui, que embora haja ainda muitas representações de engenheiras $e$ cientistas estereotipadas, a maior parte dos filmes contemporâneos apresenta também engenheiras e mulheres cientistas em posições profissionais de elevado status (Steinke, 2005). Contudo, imagens que mostram as interações entre tais mulheres e colegas homens tendem a reforçar narrativas tradicionais sobre o papel da mulher na ciência, por meio de "formas estereotipadas escondidas e sutis" (Steinke, 2005:27).

Pesquisas realizadas com crianças e adolescentes também mostram a força $e$ a persistência dos estereótipos $e$ das discriminações de gênero. No primeiro estudo efetuado com o Draw-A-Scientist-Test - DAST, teste de desenhar um cientista (Chambers, 1983), praticamente todas as meninas de um grupo de cerca de cinco mil crianças, com exceção de apenas 28, desenharam um cientista homem. Nenhum menino desenhou uma cientista. Pesquisas sucessivas mostraram maior diversificação, mas, ainda hoje, em centenas de testes efetuados em diversos países, a maioria das crianças, em todos os países pesquisados, retrata cientistas homens e quase que exclusivamente brancos (para uma revisão da bibliografia, ver Steinke et alii,

${ }^{2}$ Ver, por exemplo, a reportagem do jornal The Guardian (2012). 
2007). Em estudos análogos, mas mais aprofundados (com um setting de story-telling ilustrado e grupos focais), crianças italianas, $e$, posteriormente, brasileiras, desenharam cientistas mulheres com certa frequência, mas inseridas em um contexto narrativo em que alguma figura masculina de certa forma autorizava ou legitimava o protagonismo da cientista mulher: a jovem mulher, em muitos casos imaginados pelas crianças, era cientista por conta do fato de o pai, ou o tio, ser um cientista "famoso" (Castelfranchi et alii, 2006; Magalhães et alii, 2014).

Flicker (2003), por sua vez, chama a atenção para a preponderância de homens em papéis importantes de cientistas em todas as mídias. Para a autora, que realizou um estudo baseado em interpretação sociológica em 60 filmes, as mulheres cientistas na ficção tendem a ser bem diferentes de seus colegas masculinos: elas são em geral bonitas $e$, em relação a suas qualificações, inacreditavelmente jovens. Além disso, têm um corpo de modelo, são magras, vestem-se provocativamente e por vezes usam óculos. Mas, quando trabalham em equipes, em geral estão subordinadas a homens. Ao realizar seu trabalho, lançam mão da intuição e de elementos emocionais; não costumam apresentar a separação entre emotividade e racionalidade científica frequentemente ressaltada em seus colegas masculinos. Portanto, segundo Flicker (2003), são levadas menos a sério como "cientistas".

Whitelegg et alii (2008) investigaram as representações de gênero de cientistas, tecnologistas, engenheiros e matemáticos nos programas de televisão do Reino Unido. Seus resultados também mostraram um universo dominado por homens, mas sinalizaram que isso varia conforme o tipo de programa. Segundo eles, a diferença não seria tão gritante nas notícias. Contudo, outro estudo também no Reino Unido sugere resultados diferentes para a mídia impressa: a análise de 1.503 artigos publicados na imprensa britânica por um período de seis meses demonstra que jornalistas citam mais fontes científicas do sexo masculino, numa proporção de cinco homens citados para cada mulher (UK Resource Center for Women in Science, Technology and Engineering, 
2008; Kitzinger et alii, 2008). O mesmo desequilibrio é observado no caso de entrevistas longas, na mesma proporção de cinco para um. Além disso, jornalistas tendem a fazer mais comentários sobre a aparência quando a pessoa entrevistada é do sexo feminino: metade das descrições feitas a mulheres cientistas mencionam a roupa, o físico ou o cabelo, enquanto isso ocorre em apenas um quinto dos homens entrevistados.

Em estudo feito na TV nos Estados Unidos, Long et alii (2010) mostraram que as representações de personagens cientistas em programas usualmente vistos por jovens em idade escolar tendem a seguir o estereótipo de homem, branco, inteligente, solteiro, que não tem filhos e com uma posição alta na carreira científica. A presença maior de homens cientistas se vê tanto em número de personagens, como em número de cenas. Segundo os autores, seus resultados sugerem aos telespectadores que a ciência é uma carreira essencialmente para homens. Além disso, igualmente ao que ocorre com homens, a representação da mulher cientista é de caucasiana. Long, Boiarsky e Thayer (2001) chamam a atenção para a necessidade de se levar em consideração aspectos raciais como complementares na reprodução midiática das desigualdades e dos estereótipos às representações de homens e mulheres nos meios de comunicação.

Por fim, Ribeiro e Rohden (2009), a partir de outra perspectiva, analisam dois programas do Globo Repórter, veiculado em horário nobre pela Rede Globo de Televisão, para mostrar como tais produções narram e contextualizam as diferenças de gêneros. Mais uma vez - afirmam as autoras - a mídia, ao apresentar as chamadas "bases científicas das diferenças entre homens e mulheres", privilegia as ciências biológicas para essas discussões, contribuindo para a reprodução da naturalização da diferença de gênero, e para "a desvalorização e o apagamento da importância das pesquisas na área social para essas questões" (Ribeiro; Rohden, 2009:296). E destacam:

A princípio, não haveria problema em constatar tais diferenças [biológicas, entre sexos], mas o preocupante é 
que a construção social dessas clivagens opera sempre no sentido de reificar hierarquias pré-estabelecidas que circunscrevam o gênero (Ribeiro; Rohden, 2009:297).

Como vimos, portanto, há uma literatura rica, brasileira $e$ internacional, sobre os processos e os obstáculos que as mulheres cientistas enfrentam para ser reconhecidas como profissionais $e$ figuras públicas, bem como sobre os mecanismos de reprodução das desigualdades de oportunidades e de reforço dos estereótipos de diferenças de gênero. Menos ampla é a produção de conhecimento que foca especificamente as narrativas $e$ representações midiáticas sobre mulheres cientistas. Sobretudo, no que diz respeito à perspectiva de gênero como parte central das análises sobre ciência e tecnologia nos meios de comunicação, verificamos que a maior parte da literatura existente está focada em contextos distintos do brasileiro. Além disso, boa parte dela não se refere a representações em notícias, mas em filmes, literatura popular, quadrinhos. No Brasil, assim como na América do Sul, há poucos grupos de investigação e reduzida produção acadêmica sobre a presença da ciência e tecnologia nos meios de comunicação locais, assim como sobre a relação ciência, tecnologia e gênero nesses meios. Este estudo visou contribuir para preencher essa lacuna, investigando as especificidades dos mecanismos de apagamento, dos processos de invisibilidade da mulher como figura pública e dos filtros que reafirmam as separações tradicionais que associam as mulheres à esfera doméstica e íntima, à emotividade e ao corpo (Biroli, 2010), no caso da ciência e no âmbito da produção de notícias televisivas. ${ }^{3}$

Nosso estudo possui particular relevância também porque a TV é uma das principais fontes de informações sobre temas de ciência e tecnologia (C\&T) para o público geral (National Science Foundation, 2012; European Commission, 2007; Asociación Para La Investigación de Medios de Comunicación, 2008; Hepeng, 2006). Isso

3 O projeto de pesquisa ao qual este artigo está relacionado contou com apoio do CNPq, em edital destinado a estudos de gênero. 
ganha particular importância no Brasil, onde a televisão está presente em 97,1\% dos domicílios brasileiros, de acordo com a Pesquisa Nacional por Amostra Domiciliar de 2014 do IBGE (2014) e onde uma parcela significativa da população tem acesso limitado à educação científica formal e também a outras fontes ou espaços de democratização do conhecimento. Enquete nacional realizada pelo Ministério da Ciência, Tecnologia e Inovação e pelo Centro de Gestão e Estudos Estratégicos, em 2015, mostrou que 61\% da população brasileira têm bastante interesse em temas de ciência $e$ tecnologia, sendo a TV o veículo de comunicação mais usado para buscar informações na área (ver Percepção Pública de C\&T no Brasil, 2015).

Nesse sentido, a reflexão em torno do gênero na comunicação massiva de ciência e tecnologia pode contribuir para caracterizar a forma pela qual as mulheres cientistas são representadas em telejornais e o papel desse meio na conformação de representações da mulher cientista entre determinados segmentos do público. Também permite compreender melhor as dinâmicas e tendências do jornalismo de ciência e analisar como a comunicação desses temas, levando-se em conta a abordagem de gênero, pode contribuir para a consolidação de um país mais inclusivo. Como apontado por estudos recentes (por exemplo, Stekolschik et alii, 2010), a comunicação pública da ciência e da tecnologia cumpre um papel significativo, não apenas em sua função informativa e formativa de cidadãos e especialistas, mas também ao exercer uma influência significativa na consolidação de vocações científicas nos países latino-americanos.

\section{O desenho metodológico}

Neste estudo, analisamos as representações de cientistas, sob a perspectiva de gênero, na cobertura de ciência e tecnologia de dois programas televisivos no Brasil: um telejornal (Jornal Nacional) e um programa em formato de variedades (Fantástico), ambos produzidos e transmitidos pela Rede Globo. Trata-se de 
dois programas entre os de maior audiência e penetração no Brasil, com público pertencente a todos os grupos socioeconômicos, mas profundamente diferentes. O Jornal Nacional é uma das fontes principais de notícias diárias para os brasileiros e as brasileiras e é caracterizado pelo formato clássico $e$ o modo de produção editorial dos telejornais de notícias. Já o Fantástico, programa de atualidade de periodicidade semanal, tem todas as marcas do chamado infotainment, a narração de notícias $e$ de não ficção, com função de entretenimento, e seu discurso é fortemente conotado por sua colocação no lazer dominical de seus públicos. Embora nos últimos anos ocorreram mudanças marcantes na esfera televisiva, especialmente por causa da força crescente da informação digital e via redes sociais, a televisão, especialmente com seus programas em horário nobre e veiculados por grandes redes, e ainda mais os de notícias e o infotainment, ainda é fonte hegemônica de informação e de difusão de agenda e representações sociais para os brasileiros.

A diversidade dos dois formatos foi central para esta pesquisa: permitiu mapear imagens e narrativas da presença de homens e mulheres cientistas em dois contextos discursivos $e$ estéticos distintos, e explorar se as conotações com as quais as mulheres são representadas e ouvidas mudam quando a moldura narrativa é a da transmissão "séria e objetiva" do jornal noticioso, $e$ quando, ao contrário, é de entretenimento, curiosidade $e$ histórias de vida estão sob os holofotes. Como veremos, de fato, a presença da ciência e das mulheres muda nos dois contextos.

Nosso período de análise foi de 12 meses, entre abril de 2009 e março de 2010. Trata-se de um ano particularmente relevante do ponto de vista de eventos com marcas tecnológicocientíficas, que atingiram a agenda pública brasileira $e$ mundial $e$ levaram os jornalistas a buscar numerosas fontes científicas. Em 2009, por exemplo, ocorreu um grande terremoto na Itália, na região da cidade de Áquila, evento que levou à condenação de cientistas por não terem-no previsto; e, sucessivamente, outro tremor foi detectado, mais grave, na Indonésia. Outros eventos marcantes daquele ano: foi o Ano internacional da Astronomia, 
houve polêmicos testes de mísseis norte-coreanos; foi encontrado um fóssil considerado do mais antigo ancestral conhecido pelos homens; foram comemorados os 40 anos da chegada à Lua, e a descoberta de água nela; registrou-se um planeta extra-solar com a possível presença de água; houve um grande apagão de energia no Brasil; ocorreu a primeira extração de petróleo na camada do pré-sal; e, sobretudo, houve o medo mundial pelo alastramento da pandemia da gripe H1N1. O início de 2010, por sua vez, foi marcado por chuvas $e$ enchentes que causaram mortes $e$ destruição (e controvérsias sociotécnicas) no estado de Rio de Janeiro; pelo catastrófico terremoto no Haiti; por diversos desastres socioambientais no mundo, associados à mudança climática; e pelo reconhecimento de um novo elemento químico, o Copérnico.

No caso do Jornal Nacional, consolidamos a amostra de acordo com a metodologia da "semana construída" (Stempel, 1989; Krippendorff, 1990), pela qual se reduz consideravelmente o volume de informações a ser analisado - permitindo que cada dia da semana tenha a mesma probabilidade de ser representado na amostra -, mas é assegurada a validade estatística da amostra construída. Em nossa análise, consideramos uma "semana construída" por mês (de segunda-feira a sábado) para o Jornal Nacional; a amostra equivale a 12 "semanas construídas" durante um ano, ou seja, 72 episódios do Jornal Nacional. Trata-se de uma amostra estatisticamente representativa da programação do ano inteiro observado. Isto significa que as porcentagens identificadas, por exemplo, relacionadas à presença de mulheres cientistas, bem como as demais variáveis mensuradas, seriam, com pequena margem de erro, as mesmas caso tivéssemos analisados a produção total do ano. No caso do Fantástico, de periodicidade semanal, foram selecionados e examinados praticamente todos os episódios ao longo do ano (51 programas). ${ }^{4}$

Cada programa foi visto na íntegra, visando selecionar as matérias de ciência. Para a definição de quais matérias deveriam

${ }^{4}$ Apenas um programa não foi analisado, por problemas técnicos. 
entrar, construímos um protocolo com base na proposta de Rondelli (2004), consolidado por pesquisadores da Rede IberoAmericana de Monitoramento e Capacitação em Jornalismo Científico (Massarani; Ramalho, 2012). ${ }^{5}$

Para configurar como matéria de ciência e ser incluída na amostra para análise, a unidade noticiosa deveria atender pelo menos a um dos seguintes requisitos: mencionar explicitamente o nome de algum cientista, pesquisador, professor universitário ou especialista em geral (desde que aparecessem vinculados a uma instituição científica e comentassem temas relacionados à ciência); mencionar instituições de pesquisa e universidades; mencionar dados científicos ou resultados de investigações; mencionar política científica; tratar de divulgação científica. Os últimos dois critérios, embora levem a incluir matérias não necessariamente ligadas de forma direta a alguma pesquisa, descoberta ou invenção, são importantes. Isto porque, por um lado, as discussões sobre política científica e tecnológica e sobre difusão do conhecimento científico são parte integrante da construção do debate sobre a ciência e tecnologia, seu papel na sociedade, sua difusão e apropriação social, portanto elementos centrais para entender as representações midiáticas sobre C\&T. Por outro lado, nesses dois eixos se encontram elementos simbólicos importantes para entender o campo discursivo e os enquadramentos a partir dos quais C\&T são narradas e posicionadas: um campo discursivo, como mostramos, profundamente atravessado por diferenças $e$ estereótipos de gênero.

As matérias assim coletadas foram submetidas à análise com base em uma triangulação entre técnicas de cunho quantitativo e qualitativo. Em primeiro lugar, foi efetuada uma análise de conteúdo com base em um protocolo também desenvolvido no âmbito da Rede Ibero-Americana de Monitoramento e

${ }^{5}$ Agradecemos a Moacyr Anício e Lízia Mara Caetano, estudantes da Universidade Federal de Minas Gerais à época da pesquisa, que nos auxiliaram na codificação das informações. Agradecemos, também, a Marina Ramalho, Luis Henrique Amorim e Gabriela Reznik pela participação no projeto. 
Capacitação em Jornalismo Científico (Massarani; Ramalho, 2012), que inclui, além de variáveis e categorias clássicas da análise de conteúdo, uma parte de codificação dos enquadramentos (frames). A definição dos enquadramentos igualmente seguiu o protocolo desenvolvido pela Rede, tendo como ponto de partida modelo proposto por Nisbet, Brossard e Kroepsch (2003). Cada matéria pôde ser classificada em até três enquadramentos diferentes, entre os seguintes: nova pesquisa, novo desenvolvimento tecnológico, antecedentes/background científico, impacto da ciência e da tecnologia na sociedade, ética e moral, estratégia política/políticas públicas e regulação, controvérsia científica, incerteza científica, personalização e dimensão cultural da ciência (para o detalhamento dos enquadramentos, ver Massarani e Ramalho, 2012).

Paralelamente à análise de conteúdo, realizamos uma análise qualitativa visual dos trechos de matérias em que aparecem cientistas, tendo como ponto de partida estudos realizados sobre a representação de mulheres cientistas em meios de comunicação (Flicker, 2003; Steinke, 2005; Long et al, 2010). Criamos um protocolo de análise em que cada trecho de vídeo em que aparecesse um cientista correspondia a uma unidade de análise. Foram codificados os seguintes itens:

- Idade aparente: "jovem", para idade aparente de até 40 anos; "sênior", para idade aparente acima de 60 anos; "indeterminada", quando a idade aparente é intermediária - entre 41 e 59 anos - ou quando há discordância entre codificadores. Considerando o grau de subjetividade dessa variável, analisamos também os Currículos Lattes, quando disponíveis, como no caso de pesquisadores brasileiros, tomando o ano declarado de graduação como forma de estimar a faixa etária do entrevistado.

- Cor da pele: seguindo classificação proposta pelo Instituto Brasileiro de Geografia e Estatística (IBGE), a saber, branco, preto, amarelo, pardo e indígena (IBGE, 2011).

- Papel na matéria jornalística como fonte: cientista entrevistado como fonte externa, para comentar pesquisa de outros cientistas; 
pesquisador integrante do grupo que fez a descoberta ou a pesquisa que originou a notícia; líder ou coordenador do grupo que fez a descoberta ou a pesquisa que originou a notícia.

- Ícones da ciência: presença de ícones visuais clássicos na representação dos cientistas, usualmente associados a estereótipos da ciência ou dos/das cientistas (registro livre de qualquer ícone que surgisse, por exemplo, óculos, jaleco, tubos de ensaio, livros etc.). ${ }^{6}$

Para ser considerada "cientista", e passar a compor unidade de análise, a pessoa entrevistada em uma matéria tinha de ser explicitamente identificada como tal, nos créditos dados pelo programa, ou estar associada a uma instituição de pesquisa. Estamos conscientes que nem todas as pessoas associadas a uma instituição de pesquisa necessariamente são cientistas, ou fazem pesquisa, mas consideramos que a margem de erro sistemático associada a essa forma de selecionar as matérias era suficientemente pequena. Além disso, nosso estudo não tem como objetivo identificar quais são os "verdadeiros" cientistas entrevistados na mídia, mas, sim, ver que tipo de características estão associadas a pessoas que, no discurso midiático, são associadas à pesquisa científica. Em outras palavras, era importante ver não quem são os cientistas para os próprios cientistas e suas instituições, mas quem são os cientistas para os públicos: um entrevistado pertencente a uma instituição de pesquisa comentando uma notícia de ciência é, sem dúvida, no olhar do público, parte do universo semântico da narrativa sobre ciência e cientista.

Os dados foram analisados com auxílio do software QDA Miner, da Provalis Research, que possibilita uma análise de

6 Os óculos, obviamente, são de uso frequente na população em geral, mas representam também elemento importante do vocabulário visual utilizado na representação ficcional dos cientistas e dos intelectuais, sendo, portanto, importante detectar se sua presença na narrativa jornalística demonstra diferenças de gênero significativa ou possui conotações semânticas. 
modelo misto quali-quantitativa, de conteúdo, lexicográfica, semântica etc. (Lewis; Maas, 2007).

\section{Resultados e discussão}

As diferenças de gênero em números

No total, obtivemos 188 matérias coletadas seguindo a metodologia descrita anteriormente. Ao analisar essas matérias, emergem diferenças significativas no que se refere ao gênero dos cientistas nelas abordados (Figura 1): há um maior número de matérias (75, ou seja, 39,9\%) contendo apenas cientistas homens, ou nenhum cientista (67 matérias, 35,6\%). Aparecem cientistas mulheres em apenas 48 matérias $(24 \%)$ - em 31 delas (16,5\%) sendo apenas mulheres; nas demais (8,0\%), 15 cientistas de ambos os sexos.

Figura 1 - Presença de cientistas nas matérias de ciência analisadas, por gênero

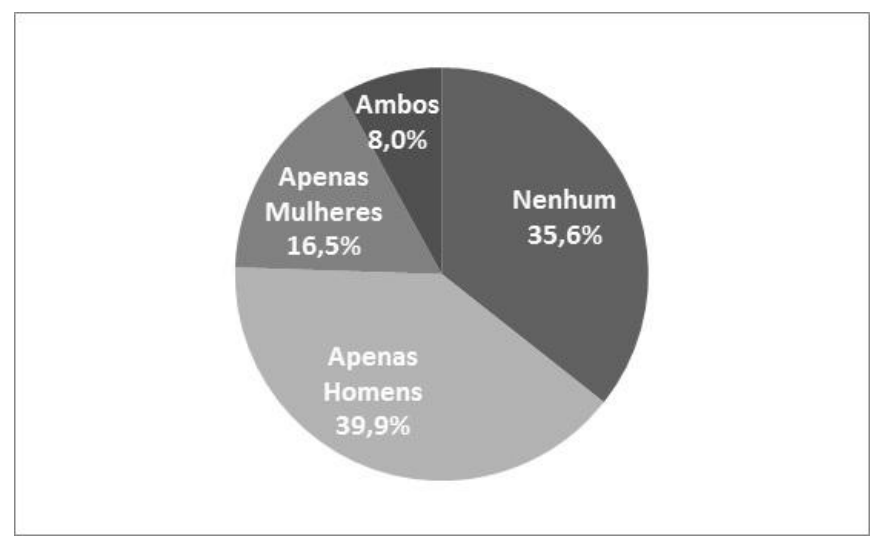

Fonte: elaboração própria.

Também emergem diferenças significativas na cobertura por gênero quando comparamos os dois programas (Figura 2): se, por 
um lado, no Fantástico a presença de cientistas entrevistados é muito mais frequente (por conta do contexto de produção da narrativa, centrado em imagens e histórias humanas), também maior é a fração de cientistas homens, sinal de que a narrativa sendo desenvolvida reproduz a de uma ciência masculina.

Figura 2 - Presença de cientistas em cada veículo analisado, por gênero

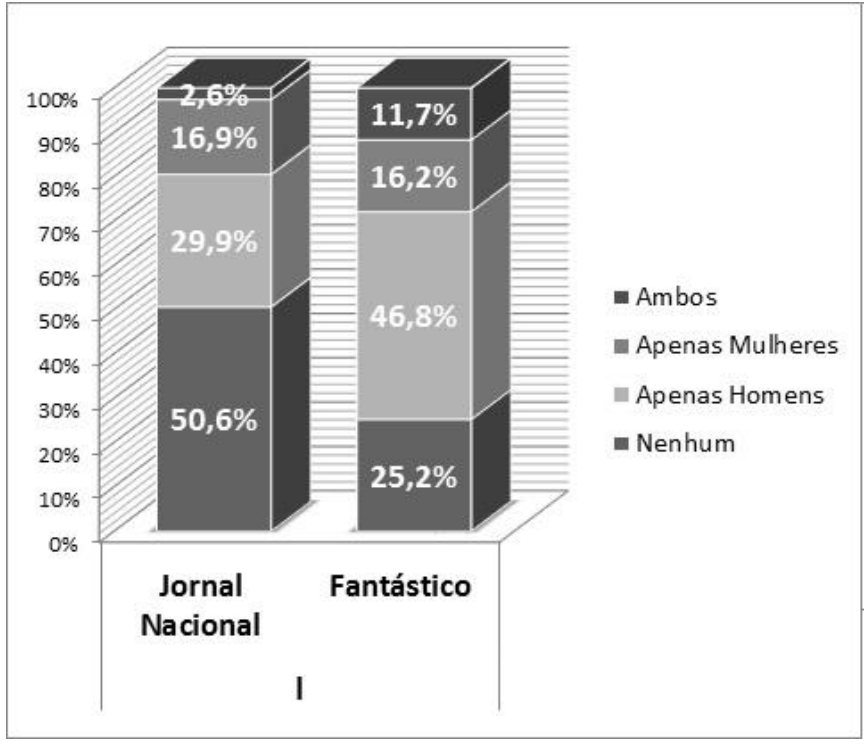

Fonte: elaboração própria.

As matérias sobre ciência do Fantástico são, em média, mais longas (duração média de uma matéria de 5 minutos e 46 segundos, contra 2 minutos e 9 segundos no $J M$ ), fator que permite que elas tenham mais chances de conter entrevistas ou trechos com cientistas. As matérias de ciência em que não aparece nenhum cientista são, no Fantástico, apenas 25,2\%, contra 50,6\% no $J N$. A média de cientistas entrevistados por matéria no $J N e ́$ de 0,58 contra 1,13 no Fantástico.

No entanto, o maior espaço à disposição no Fantástico não faz com que o programa dê maior atenção às cientistas mulheres: embora mulheres cientistas apareçam em 27,9\% das matérias 
desse programa, contra $19,5 \%$ no $J N$, a proporção de matérias contendo apenas homens cientistas é de $46,8 \%$, contra $29,9 \%$ no JN. Já a proporção de matérias que contêm apenas mulheres permanece igual em ambos os programas, enquanto aumenta a fração de matérias que contêm ambos os sexos (de 2,6\% para $11,7 \%$ ). No total (Figura 2), homens (exclusivamente ou junto com mulheres) aparecem em 32,5\% das matérias no $J N$ e 58,5\% no Fantástico (diferenças estatisticamente significativas com $\mathrm{p}<0.01$ ).

Outra diferença relevante entre os dois programas se encontra no papel do entrevistado enquanto fonte. No Fantástico, a grande maioria $(86 \%)$ dos cientistas entrevistados ou que comentam alguma notícia não pertence ao grupo de pesquisa que originou a notícia. No $J N$, metade dos cientistas entrevistados pertence ao grupo diretamente envolvido na pesquisa ou descoberta que originou a notícia, sendo $38 \%$ integrantes do grupo e $11 \%$, líderes $(\mathrm{p}<0.001)$. Há indícios de que o gênero também tem alguma influência na tipologia do entrevistado: apenas $25 \%$ dos líderes de pesquisa entrevistados são mulheres, uma fração consistente com $\mathrm{o}$ número de mulheres entrevistadas; $\mathrm{a}$ porcentagem sobe para $33 \%$ quando o entrevistado é uma cientista comentando uma pesquisa da qual não participou. Contudo, tal diferença não resultou estatisticamente significativa: representa apenas um indício a ser testado com uma amostra maior de matérias.

Além do número de matérias contendo mulheres cientistas (muito menor do que as com homens), é interessante investigar se há diferenças na duração das matérias no caso em que a reportagem veicula um homem ou uma mulher cientista. Nossos resultados mostram que tal diferença não é significativa no caso do JN, mas é marcada no caso do Fantástico: nesse segundo programa, matérias contendo apenas homens entrevistados são significativamente mais longas (6min e 16s de duração em média) do que aquelas que contêm só mulheres (4min e 26 seg).

Se a duração e o número de matérias parecem privilegiar um universo masculino, as diferenças de gênero atravessam 
também o tema, a fonte, o tratamento e o enfoque narrativo da matéria.

Outro fator que influencia de maneira significativa a probabilidade de uma matéria conter uma mulher cientista é o país da fonte entrevistada. No total, como vimos, $25 \%$ dos entrevistados são mulheres. Mas quando são entrevistados brasileiros (130 cientistas no corpus coletado, equivalente a $77 \%$ do total), a chance de se ter uma pesquisadora mulher aumenta para $35 \%$. Em oposição, quando o entrevistado é um cientista de outro país, a fração de mulheres é apenas $7 \%$ (diferenças significativas com $\mathrm{p}<0.001$ ).

A área de conhecimento tratada na matéria também está associada à diferença de gênero. As áreas em que a proporção de mulheres cientistas é mais expressiva são, respectivamente, ciências biológicas ( $42 \%$ das matérias contendo mulheres, contra $25 \%$ da média geral das matérias) e ciências sociais e humanidades ( $41 \%$ das matérias contendo mulheres; $\mathrm{p}<0.05$ ). Tais diferenças são significativas especialmente no caso do Fantástico, em que a porcentagem de mulheres cientistas em matérias cobrindo a área de biológicas é de $59 \%{ }^{7}$

$\mathrm{O}$ enfoque narrativo também influencia a probabilidade de se ter uma mulher cientista na reportagem. Em particular, quando um dos enfoques presentes na matéria é a narrativa de uma nova investigação, a chance de se ter uma cientista entrevistada é menor: há mulheres em $17 \%$ das matérias que possuem tal enfoque, contra $32 \%$ das demais $(\mathrm{p}<0.05)$.

Quando o enfoque da matéria é sobre o impacto social da $\mathrm{C} \& \mathrm{~T}$, também a chance de se ter uma mulher é menor (elas aparecem em $14 \%$ das matérias, contra $28 \%$ das matérias não contendo tal enfoque; $\mathrm{p}<0.05$ ). Além disso, as mulheres cientistas aparecem em apenas $4 \%$ das matérias que fazem menção a algum

7 A análise estatística mostra que as diferenças identificadas no caso do $J N$ podem ser por conta do puro acaso na seleção das matérias: são diferenças não significativas. No caso do Fantástico, ao contrário, podemos dizer que há, de fato, uma associação estatística entre a presença de mulheres nas matérias e a área de conhecimento principal coberta pela notícia. 
risco associado a C\&T, contra $27 \%$ das demais: um indício, a ser explorado, para verificar a hipótese de haver um preconceito de gênero quando o tipo de expert procurado precisa se posicionar ou comentar sobre implicações da ciência em situação de controvérsia ou conflito.

\section{A narrativa visual}

Quando analisamos além do conteúdo das matérias sua narrativa visual as evidências de que as representações sobre ciência e cientistas nos programas analisados remetem principalmente a um universo masculino se confirmam e ganham novos contornos.

$\mathrm{Na}$ análise visual, a unidade de análise foi cada fragmento de vídeo em que aparece algum cientista (portanto, em alguns casos, uma matéria compreende mais de uma unidade de análise). A figura dominante de cientista presente nas matérias é a de um homem, maduro (idade aparente acima de 40 anos) e branco. Das 169 unidades identificadas em nosso corpus, 116 são ocupadas por cientistas homens (equivalente a 68,6\%). Em 60 das 169 unidades, o cientista entrevistado (homem ou mulher) é "maduro" (idade aparente acima de 60 anos). ${ }^{8}$ A grande maioria dos cientistas representados em nossa amostra (154, ou seja, $91,1 \%)$ é branca. Os demais são assim distribuídos: sete asiáticos $(4,1 \%)$, seis pardos $(3,5 \%), 1$ negro $(0,6 \%)$ e 1 indígena $(0,6 \%)$.

Emerge um dado interessante quando cruzamos gênero com idade dos entrevistados: as mulheres entrevistadas tendem a ser mais jovens (ou a ter aparência mais jovem) que os homens. Apenas $18,3 \%$ dos cientistas homens entrevistados aparentam ter menos de 40 anos de idade, em contraposição a 52,8\% das mulheres (Figura 3).

\footnotetext{
8 Um dos cientistas homens entrevistados não teve sua idade computada porque a entrevista foi feita por telefone, logo não foi possível analisar características relativas à sua imagem.
} 
Figura 3 - Idade aparente dos cientistas entrevistados, por gênero

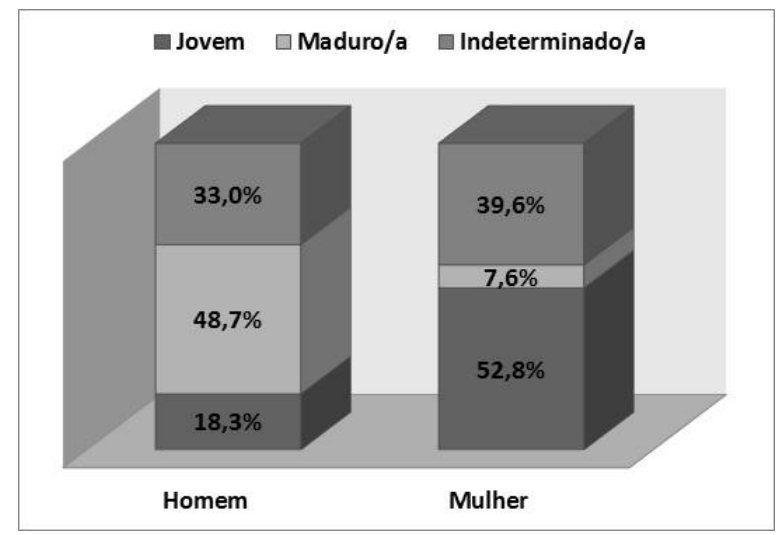

Fonte: elaboração própria.

Visto por outra perspectiva (Figura 4), as mulheres representam $57,1 \%$ dos cientistas "jovens" entrevistados (idade aparente menor que 40 anos), mas são apenas 6,7\% dos "sênior" (diferenças significativas com $\mathrm{p}<0.001$ ). Trata-se de indícios, por um lado, da crescente presença de jovens mulheres nas carreiras tecnocientíficas, mas, por outro lado, também da estrutura hierarquizada da ciência brasileira, em que as mulheres tiveram um papel crescente e marcante, mas com menor acesso a posições de poder e cargos de direção de grupos e laboratórios. 
Figura 4 - Fração de homens e mulheres entrevistados, em função da idade aparente

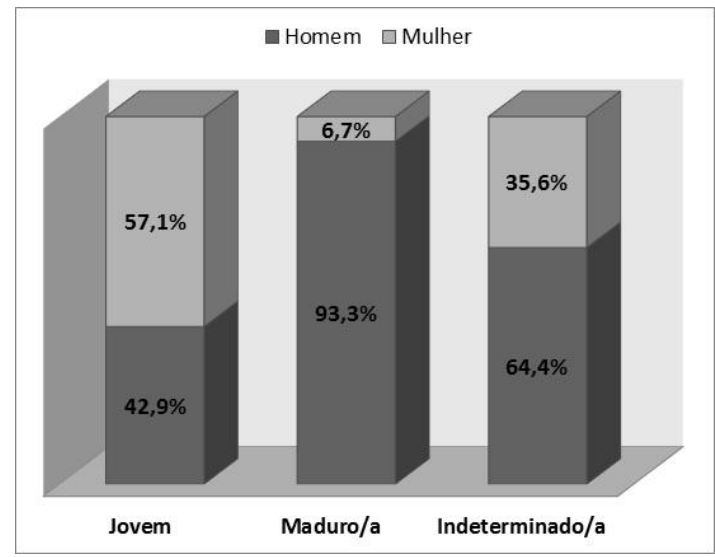

Fonte: elaboração própria.

Ao comparar os dois programas, a diferença de gênero na idade aparente dos entrevistados aparece como mais marcada no Fantástico (Figura 5). Em ambos os veículos, o grupo mais representado é o de homens maduros, mas no caso do programa semanal sua proporção é maior (35,5\% dos entrevistados, contra $27.3 \%$ no caso do $J M$ ). No Fantástico, há uma proporção pequena de mulheres na faixa de idade de difícil determinação $(9,7 \%$ do total de entrevistados, contra $20,5 \%$ no $J M$. 
Figura 5 - Gênero e idade aparente dos entrevistados, em função do veículo

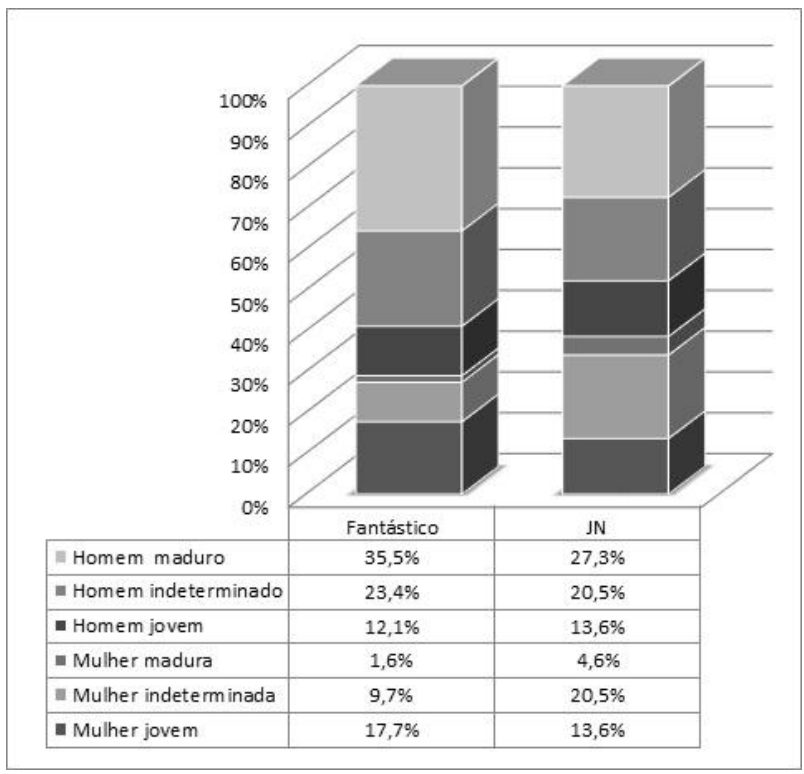

Fonte: elaboração própria.

Ícones e estereótipos da ciência apareceram com bastante frequência em ambos os programas, embora com maior ênfase em Fantástico, coerentemente com o perfil de entretenimento e narrativas espetaculares do programa. Óculos, jaleco, computadores e livros foram os ícones mais presentes, embora haja grande diversidade de outros elementos visuais, tais como papéis e documentações, equipamentos científicos ou médicos e vidrarias (Figura 5). No Fantástico, que, por ser um programa semanal de informação e entretenimento, costuma dar particular atenção à estética e à construção da narrativa visual, houve uma presença maior de elementos que constituíram os cenários narrativos visuais, tais como modelos de partes do corpo (por exemplo, um cérebro), aves taxidermizadas etc. 
Houve ligeiras diferenças de gênero no que se refere à presença de tais elementos icônicos no Fantástico. Não foram encontrados ícones em 30 das unidades contendo cientistas homens e em 15 das que contêm mulheres. No $J N$, nove trechos com cientistas homens e seis com mulheres também não apresentavam ícones. Além disso, embora os elementos mais frequentemente presentes fossem os mesmos no caso de homens $e$ mulheres, a porcentagem relativa dos mesmos foi diferente: óculos, jalecos, computadores e livros apareceram, respectivamente, em $32 \%, 26 \%, 12 \%$ e $9 \%$ das unidades com homens entrevistados, contra $23 \%, 18 \% 13 \%$ e $13 \%$ dos trechos contendo mulheres: as mulheres pesquisadoras são retratadas como menos conotadas pelos estereótipos clássicos.

\section{Considerações finais}

Nossa pesquisa ampliou as evidências disponíveis sobre as formas em que a esfera pública tende a uma construção da invisibilidade e do silenciamento da mulher, focalizando em um território menos explorado na literatura: o das representações midiáticas das mulheres cientistas, no caso específico, menos estudado, da produção de notícias televisivas no Brasil. Como vimos, embora nossos resultados corroborem alguns estudos anteriores (ver, por ex., Biroli, 2010), algumas especificidades marcantes emergem. Ao sub-representar as mulheres cientistas, $e$ ao construir um filtro semântico para sua representação, a TV brasileira tende a uma narrativa que se distancia da ciência como ela realmente é atualmente no Brasil: uma empreitada feita por, $e$ com, mulheres.

O gênero do cientista é um fator condicionante importante para a sua aparição (ou não) em matérias de ciência nos dois programas, remetendo-se a um universo preponderantemente masculino. A chance de um cientista homem aparecer em uma matéria é o dobro da de uma cientista mulher, em contraste com as reais proporções de cientistas mulheres atualmente em atividade no país: já cerca de metade da população de cientistas. 
Além disso, os trechos que contêm apenas cientistas homens entrevistados são significativamente mais longos do que aqueles com apenas mulheres. Esses dados corroboram a literatura na área, que mostra uma maior presença do homem em relação à mulher em diversos gêneros midiáticos, mas está na contramão das políticas de promoção de igualdade de gênero no Brasil da última década, que reconhecem a mídia como fundamental para a construção da imagem da mulher cientista.

Além da imagem masculina associada ao profissional da ciência nos programas analisados, a imensa maioria $(91,1 \%)$ dos cientistas veiculados nos programas analisados são brancos - em uma sociedade em que menos da metade da população se declara branca, segundo dados do IBGE (2008). Embora, como já mencionado, esta pesquisa não pretendera explorar o território da interseccionalidade, pela escassez quantitativa de entrevistados $e$ entrevistadas que não são brancas em nossa amostra, e pelos poucos dados disponíveis nas bases de dados sobre cientistas brasileiros, o dado reflete o peso de um sistema complexo de entrelaçamento do sexismo com o classismo e o racismo, e cujos efeitos são multíplices (Davies, 2002; Hooks, 2014): por um lado, pela reduzida presença de pardos, negros e indígenas na comunidade científica brasileira e, por outro lado, por uma narrativa midiática estereotipada, que reproduz e amplifica o preconceito, não dando visibilidade ao fato de que, de acordo com os dados do IBGE de 2010, 20\% dos mestres e doutores do Brasil se declaram não brancos.

A iniciativa relativamente recente do $\mathrm{CNPq}$ de introduzir a variável cor/raça no Currículo Lattes permitirá conhecer melhor, em curto prazo, a diversidade da comunidade científica brasileira, o que poderá auxiliar políticas que revertam o quadro. Também será crucial, nos próximos anos, avaliar de que forma as políticas de ação afirmativa e de cotas raciais ${ }^{9}$ podem ter um impacto na

9 Reserva de vagas em instituições públicas ou privadas para grupos específicos classificados por etnia, na maioria das vezes, negros e indígenas, conforme decisão do Supremo Tribunal Federal em 2012. 
conformação da comunidade científica, $e$ averiguar se, e em que medida, a representação dos cientistas veiculada pela mídia será influenciada em médio prazo.

A maturidade associada à imagem do cientista homem também é evidente em nossa amostra: é principalmente o rosto do homem branco e de meia idade que aparece nos programas analisados. Em contraposição, a imagem associada à mulher cientista é a de jovem. Por um lado, essa imagem da cientista mulher pode estar associada à dinâmica da consolidação da comunidade científica, cuja inserção da mulher foi tardia em decorrência da própria dinâmica da sociedade brasileira. Será interessante, em investigações futuras, analisar se a imagem mais jovial da mulher está associada às escolhas feitas pela equipe de jornalismo e produção dos programas, que costumam ter entre seus critérios de seleção o appeal midiático dos entrevistados: seria um critério de escolha de mulheres cientistas aquelas que são supostamente atraentes? Para os homens cientistas, seria percebido como mais adequado, do ponto de vista da narrativa visual e do discurso jornalístico, a representação da expertise masculina a partir da experiência e na maturidade?

Outro ponto que merece destaque é o fato de que o enfoque narrativo também influencia a probabilidade de se ter uma mulher cientista na reportagem. Quando se apresenta uma nova investigação ou a matéria trata do impacto social da C\&T, ou, ainda, menciona riscos associados à $\mathrm{C} \& \mathrm{~T}$, é menor a chance de haver uma mulher entrevistada. Esse é um indício a ser melhor explorado em novos estudos e que parece apontar para um preconceito de gênero quando o tipo de expert procurado precisa se posicionar ou comentar sobre implicações da ciência em situação de controvérsia ou conflito. Seriam esses dados indícios de percepções sociais, tão bem estudadas na literatura (ver, por exemplo, Keller, 1985; Schienbinger, 2001), que veem a mente masculina como mais imparcial, objetiva, e o feminino como o polo da corporeidade, emocionalidade e subjetividade?

No que se refere aos ícones da ciência, observamos diferenças de gênero: as mulheres estiveram menos associadas às 
imagens relacionadas aos estereótipos de cientistas. Embora as diferenças fossem pequenas nesse particular, nossos dados sugerem que homens e mulheres estão sendo representados de formas diferenciadas como cientistas.

Nosso estudo tem caráter exploratório, que, obviamente, não visa esgotar o debate sobre as desigualdades de gênero nos meios de comunicação nas representações de cientistas, mas, sim, contribuir para a análise e a interpretação de dinâmicas específicas dos estereótipos de gênero.

Além disso, o estudo, realizado ao longo de um ano, não possibilita uma perspectiva histórica que permita afirmar como as mulheres cientistas vêm sendo retratadas no Jornal Nacional e no Fantástico. Também não podemos extrapolar nossas observações para outros veículos de comunicação brasileiros ou para outros programas no mesmo canal televisivo.

Mas acreditamos que os dados apresentados, ao fornecer elementos de como a cobertura de C\&T no Jornal Nacional e no Fantástico está construindo a imagem de uma ciência bastante diferente do quadro atual, concreto, da ciência no país, trazem contribuições relevantes, sendo os programas analisados dois dos mais importantes da televisão brasileira, com grande repercussão nacional.

Se desejamos consolidar uma ciência mais inclusiva, é crucial cartografar os processos de construção da imagem midiática do profissional da ciência, tanto para identificar com mais precisão por onde passam e como se cristalizam a relação de poder e a subalternidade, quanto para pensar como aperfeiçoar a comunicação pública da ciência na mídia, de forma que estereótipos e preconceitos sejam superados.

\section{Referências bibliográficas}

ABREU, Alice. Women for Science in Brazil. International Sociological Association e-bulletin (16), Madrid, julho 2010, pp.64-89.

ASOCIACIÓN para la investigación de medios de comunicación. Estudio General de Medios, Abril de 2007 a Março de 2008. Madri, AIMC, 
2008

[http://www.aimc.es/aimc.php?izq=egm.swf\&pag_html=si\&op=cuatr o\&dch $=02$ egm/24.html - acesso em: 9 abr. 2016].

BIROLI, Flávia. Gênero e política no noticiário das revistas semanais brasileiras: ausências e estereótipos. cadernos pagu (34), CampinasSP, Núcleo de Estudos de Gênero-Pagu/Unicamp, pp.269-299.

CASTELFRANCHI, Yurij et alii. Children's perceptions of science and scientists. In: Proceedings of 9th International Conference On public communication of science \& technology (pcst-9), 2006, PCST Network, Seoul [https://pcst.co/archive/pdf/Manzoli_et_al_PCST2006.pdf]

CHAMBERS, David Wade. Stereotypic Images of the Scientist: The Draw a Scientist Test. Science Education (67:2), Madison, 1983, pp.255-265.

CHIMBA, Mwenya Diana; KITZINGER, Jenny. Bimbo or boffin? Women in science: an analysis of media representations and how female scientists negotiate cultural contradictions. Public Understanding of Science (19), Thousand Oaks, 2010, pp.609-624.

CNPQ, Conselho Nacional de Desenvolvimento Científico e Tecnológico, Séries Históricas por Pesquisadores por sexo [http://lattes.cnpq.br/web/dgp/pesquisadores-por-sexo - acesso em: 6 maio 2016].

COMISSÃO EUROPEIA. Investigação e inovação: ciência no mundo feminino [http://science-girl-thing.eu/pt/sobre-este-sitio - acesso em: 23 abr. 2016].

DAVIES, Paul G. et alii. Consuming Images: How Television Commercials that Elicit Stereotype Threat Can Restrain Women Academically and Professionally. Personality and Social Psychology Bulletin (28), Thousand Oaks, Dez 2002, pp.1615-1628.

De Solla PriCE, Derek John. Little Science, Big Science and Beyond. New York, Columbia University Press, 1986.

DELAmONT, Sara. Knowledgeable Women: Structuralism and the Reproduction of Elites. London, Routledge, 1989.

DURKIN, Kevin. Children's Accounts of Sex-Role Stereotypes in Television. Communication Research (11:3), Thousand Oaks, Jul 1984, pp.341-362. 
EASLEA, Brian. The Masculine Image of Science with Special Reference to Physics: How Much does Gender Really Matter? In: HARDING, J. (ed). Perspectives on Gender and Science. London, The Falmer Press, 1986, pp.132-59.

EUROPEAN COMMISSION. Special Eurobarometer on scientific research in the media. Brusseles, EU. 2007 [http://ec.europa.eu/research/conferences/2007/bcn2007/index_en.ht m, acesso em 9 de maio de 2008 - acesso em: 23 abr. 2016].

FAULKNER, Wendy. Nuts and Bolts and People: Gender-Troubled Engineering Identities. Social Studies of Science (37), Thousand Oaks, 2007, pp.331-56.

FERREIRA, Luiz Otávio et alii. Institucionalização das ciências, sistema de gênero e produção científica no Brasil (1939-1969). Hist. cienc. saúde - Manguinhos (15), Rio de Janeiro, 2008, pp.43-71.

FLICKER, Eva. Between Brains and Breasts--Women Scientists in Fiction Film: On the Marginalization and Sexualization of Scientific Competence. Public Understanding of Science (12:3), Thousand Oaks, 2003, pp.307-316

FREITAS, Lucas Bueno; LUZ, Nanci Stancki. Gênero, Ciência e Tecnologia: estado da arte a partir de periódicos de gênero. cadernos pagu (49), Campinas-SP, Núcleo de Estudos de GêneroPagu/Unicamp, 2017, e174908.

Glover, Judith. Women and Scientific Employment. New York, St. Martin's Press, 2000.

GROSSI, Márcia Gorett Ribeiro et alii. As mulheres praticando ciência no Brasil. Rev. Estud. Fem (24), Florianópolis-SC , 2016, pp.11-30.

GUEDES, Moema de Castro. A presença feminina nos cursos universitários e nas pós-graduações: desconstruindo a ideia da universidade como espaço masculino. Hist. cienc. saúde Manguinhos (15), Rio de Janeiro, 2008, pp.117-132.

Guedes, Moema de Castro; Azevedo, Nara; FerreirA, Luiz Otávio. A produtividade científica tem sexo? Um estudo sobre bolsistas de produtividade do CNPq. cadernos pagu (45), Campinas-SP, Núcleo de Estudos de Gênero-Pagu/Unicamp, 2015, pp.367-399. 
HEPENG, Jepeng. TV antenna in Wuhan: the Chinese obtain most of their science from TV. SciDev.Net, 2006 [http://www.scidev.net/content/news/eng/tv-is-top-for-finding-outabout-science-in-china.cfm - acesso em: 4 abr. 2016].

HOOKS, bell. Feminist theory: from margin to center. $3^{\text {a }}$ ed. Nova Iorque, Routledge, 2014 [1984].

KelleR, Evelyn Fox. Reflection on gender and science. New Haven, University Press, 1985.

KITZINGER, Jenny et alii. Role Models in the Media: An Exploration of the Views and Experiences of Women in Science, Engineering and Technology. UK Resource Center for Women in Science, Technology and Engineering, Research Briefing, n.1, 2008.

KRIPPENDORFF, K. Metodología de análisis de contenido. Teoría y Práctica. Ediciones Paidós, Barcelona, 1990.

LEWIS, R.B.; MAAS, S.M. QDA Miner 2.0: Mixed-Model Qualitative Data Analysis Software. Field Methods (19:1), Thousand Oaks, fev 2007, pp.87-108.

LiMA, Betina Stefanello; CosTA, Maria Conceição da. Gênero, ciências e tecnologias: caminhos percorridos e novos desafios. cadernos pagu (48), Campinas-SP, Núcleo de Estudos de Gênero-Pagu/Unicamp, 2016, e164805.

LOBO, Paula; CABECINHAS, Rosa. The Negotiation of Meanings in The Evening News: Towards an Understanding of Gender Disadvantages in the Access to the Public Debate. International Communication Gazette (72:4-5), Thousand Oaks, Jun 2010, pp.339-358.

LONG, Marilee; BOIARSKY, Greg; THAYER, Greg. Gender and racial counter-stereotypes in science education television: a content analysis. Public Understanding of Science (10:3), Thousand Oaks, Jul 2001, pp.255-269.

LONG, Marilee et alii. Portrayals of Male and Female Scientists in Television Programs Popular Among Middle School-Age Children, Science Communication (32:3), Thousand Oaks, 2010, pp.356-382.

MAGALHÃES, Bárbara et alii. In: 2014 International Conference On Public Communication Of Science \& Technology, Salvador, 2014. 
MASSARANI, Luisa; RAMALHO, Marina (org.). Monitoramento $e$ capacitação em jornalismo científico: a experiência de uma rede ibero-americana. Rio de Janeiro, Museu da Vida, Centro Internacional de Estudios Superiores de Comunicación para América Latina, 2012 [http://www.museudavida.fiocruz.br/media/monitoramento-ecapacitacao-em-jc.pdf - acesso em: 15 abr. 2016].

Melo, Hildete Pereira de; OliveIRA, André Barbosa. A produção científica brasileira no feminino. cadernos pagu (27), Campinas-SP, Núcleo de Estudos de Gênero-Pagu/Unicamp, dez. 2006, pp.301331.

MERTON, Robert K. The Sociology of Science: Theoretical and Empirical Investigations. Ed. N. W. Storer. Chicago, University of Chicago Press, 1973.

MINISTÉRIO da Ciência, Tecnologia e Inovação. Centro de Gestão e Estudos Estratégicos. Percepção pública de C\&T no Brasil 2015. [http://percepcaocti.cgee.org.br/wpcontent/themes/cgee/files/sumario.pdf - acesso em: 6 maio 2016].

NATIONAL SCIENCE FOUNDATION. Science and technology: public attitudes and understanding. Science and Engineering Indicators 2012 [www.nsf.gov/statistics/seind12/c7/c7h.htm - acesso abr. 2016].

NISBET, Matthew et alii. Framing Science - The Stem Cell Controversy in an Age of Press/Politics. Press/Politics (8:2), Thousand Oaks, 2003, pp.36-70.

OrensteIn, Peggy. School Girls. New York, Doubleday, 1994.

POTTS, Richard; MARTINEZ, Isaac. Television viewing and children's beliefs about scientists. Journal of Applied Developmental Psychology (15:2), Amsterdam, Abr-jun 1994, pp.287-300.

RiBEIRO, Cláudia Regina; RoHDEN, Fabíola. A ciência na mídia e as estratégias de reafirmação da bipolaridade entre os gêneros: o caso do Globo Repórter. cadernos pagu (32), Campinas-SP, Núcleo de Estudos de Gênero-Pagu/Unicamp, 2009, pp.267-299.

RIVADENEYRA, Rocío. Do You See What I See? Latino Adolescents' Perceptions of the Images on Television. Journal of Adolescent Research (21:4), Thousand Oaks, Jul 2006, pp.393-414. 
RONDELLI, Daniela. A ciência no picadeiro: Uma análise das reportagens sobre ciência no programa Fantástico. Dissertação (Mestrado em Comunicação Social) Universidade Metodista de São Paulo, 2004.

ROSSITER, Margaret. Women Scientists in America: Struggles and Strategies to 1940. Baltimore, Johns Hopkins University Press, 1982.

SCHIENBINGER, Londa. O feminismo mudou a ciência? Bauru, SP, EDUSC, 2001.

SECRETARIA Especial de Políticas para as Mulheres. Presidência Da República. Pensando gênero e ciência. Encontro Nacional de Núcleos e Grupos de Pesquisas - 2005-2006. Brasília, Secretaria Especial de Políticas para as Mulheres, 2006 [http://200.130.7.5/spmu/docs/encontro_genero.pdf - acesso em: 20 abr. 2016].

Sismondo, Sergio. An Introduction to Science and Technology Studies. West Sussex, Wiley-Blackwell, 2010.

STEINKE, J. Science in cyberspace: science and engineering World Wide Web sites for girls. Public Understandig of Science (13), Thousand Oaks, 2004, pp.7-30.

STEINKE, J. Cultural Representations of Gender and Science: Portrayals of Female Scientists and Engineers in Popular Film. Science Communication (27), Thousand Oaks, 2005, pp.27-63.

STEINKE, J. et alii. Assessing Media Influences on Middle School-Aged Children's Perceptions of Women in Science Using the Draw-AScientist Test (DAST). Science Communication (29:1), Thousand Oaks, 2007, pp.29-35.

STEINKE, Jocelyn et alii. Gender Differences in Adolescents' Wishful Identification with Scientist Characters on Television. Science Communication (34:2), Thousand Oaks, 2011, pp.163-199.

STEKOLSCHIK, Gabriel et alii. Does the public communication of science influence scientific vocation? Results of a national survey. Public Understanding of Science (19), Thousand Oaks, 2010, pp.625-637.

TABAK, Fanny. O Laboratório de Pandora. Rio de Janeiro, Garamond, 2002. 
THE GuARDIAN. Science: it's a girl thing! $A$ viral fiasco [http://www.theguardian.com/science/blog/2012/jun/29/science-girlthing-viral-fiasco - acesso em: 23 abril 2016].

UK RESOURCE Center for Women in Science, Technology And Engineering. Gender, Stereotypes and Expertise in The Press: How Newspapers Represent Male and Female Scientists. Research Briefing, n. $5,2008$.

WHITELEGG, Elizabeth et alii. (In)visible Witnesses: Investigating gendered representations of scientists, technologists, engineers and mathematicians on UK children's television. UK Resource Centre for Women in Science, Engineering and Technology, Bradford, UK, 2008.

ZUCKERMAN, Harriet. Deviant Behavior and Social Control in Science. In: SAGARIN, E. Deviance and Social Change. London, Sage, 1977, p.87138.

\section{Fontes:}

IBGE. Características étnico-raciais da população - um estudo das categorias de classificação de cor ou ração 2008. Rio de Janeiro, IBGE, 2011 [http://www.ibge.gov.br/home/estatistica/populacao/caracteristicas_rac iais/PCERP2008.pdf - acesso em: 16 abr. 2016].

IBGE. Síntese de Indicadores da Pesquisa Nacional por Amostra Domiciliar 2014 (PNAD). Rio de Janeiro, IBGE [http://www.ibge.gov.br/home/estatistica/populacao/trabalhoerendime nto/pnad2014/sintese_defaultxls.shtm - acesso em: 6 maio 2016].

LATTES. Painel Lattes - Distribuição por sexo, faixa etária e grande área de atuação. CNPq, Brasília [http://estatico.cnpq.br/painelLattes/sexofaixaetaria/ - acesso em: 6 maio 2016]. 